\title{
Landscape Accessories in the Landscape Design of the Environmental Art
}

\author{
Ning TAO \\ Art Academy \\ Northeast Agricultural University \\ Harbin,Heilongjiang,China
}

\begin{abstract}
Along with the improvement of the living standards, people's pursuit of urban landscape design becomes new, and landscape accessory is an essential element of the modern urbanization construction; to add landscape accessory into the landscape design of the environmental art can not only can beautify the urban environment, but also can help add the artistic appeal of the urban areas. Therefore, attention paid to the landscape accessory design in the landscape design of the environmental art and designing the unique works conforming to the ecological environment according to the developing law of landscape design and the development of the modern city have promoted landscape accessories to play an important role in the landscape design of the environmental art. In landscape design, the artistic value of landscape accessories should be taken into account when meeting the needs of society; it is necessary to study and analyze the contents in landscape accessory design according to the market demand for landscape accessory design, for the purpose of improving people's understanding of landscape accessory design and reflection, edifying sentiment and maintaining mind and body, and realizing the harmony between human and nature.
\end{abstract}

Keywords- environmental art; landscape design; landscape accessory

\section{INTRODUCTION}

In the landscape design of the environmental art, it is necessary for the designers to give full consideration to the role of landscape accessories and pay attention to the collocation of landscape design in space and color, so that excellent works is designed. In the landscape design process based on the environmental art, the perspective of environmental art should be always rooted to analyze the characteristics and connotation of the environmental art, so that a healthy and rich environment is created for people's work and life, and then the jobs related to featured landscape in landscape design should be done well. In this paper, the landscape accessories in the landscape design of the environmental art are analyzed, so as to promote landscape design and landscape accessory to play a huge role in the urban culture development.

\section{THE INTENSION OF THE ENVIRONMENTAL ART}

Environment is the foundation of the people to rely on for survival and development. It is mainly divided into four local environments. First, the natural environment refers to the ecological environment discussed by people, which consists of many elements such as mountain, water, wind, rain, thunder, and lightning. Second, the secondary environment mainly refers to that modified and processed by people and then the ornamental objects such as forest park, nature reserve, and man-made river are formed to a different degree. Third, the artificial environment mainly refers to the works of art, buildings, and landscapes constructed by human beings, and also the artificial environment system combining all sorts of environmental facilities. Finally, the social environment specifically means that with special cultural characteristics, which are formed based on economy, politics, and culture, and also is very adaptable to people's survival and development.

The environmental art refers to the green, harmony, and lasting art and science, and mainly includes urban planning, interior design, mural painting, landscape sketch, etc. It is closely related to people's work, life, entertainment, leisure, etc. Along with the continuous development of the social economy, people's living level and rising living standards are constantly improved, and also the requirements on the quality of the environmental art are becoming stricter and stricter.

\section{THE CONTENTS OF LANDSCAPE ACCESSORIES IN LANDSCAPE DESIGN}

\section{A. The Main Contents of Landscape Design}

In the landscape design of the environmental art, square, green land, garden, advertising, murals, and urban road are in the range of landscape design. Landscape accessories were originally the small and medium-sized buildings in gardens, which are the decorative facilities for people to enjoy and rest, and also to beautify the environment. In recent years, China's landscape industry has gotten a rapid development, making the scope of landscape accessories further expanded. With excellent landscape accessories, the beautiful landscape environment can be reflected; landscape environment is the background space for the landscape accessories, so the two sides are closely related and complement each other. In designing landscape accessories, top priority should be given to the perspective of environment; for the landscape accessory design integrating buildings, sculpture, painting, and plants, the selection of the materials should be based on the nature of the culture, and also the relationship with the environment should be fully treated. 


\section{B. The Color of Landscape Accessories}

To more significantly highlight the importance of landscape accessories in the urban construction, it is necessary to work hard in the color design of landscape accessories. Landscape accessory e color design consists of constructive art, vegetation collocation, environmental color collocation, etc. To better highlight the artistic effects of urban landscape, it is necessary to lay an emphasis on the color collocation of landscape accessories, and these colors often play a greater effect on people's mood, psychological change, and physiological problems, etc. In the design of landscape accessories, therefore, it is first necessary to get an understanding of urban style, the style of surrounding buildings, and the main representative colors, and then colors can be reasonably collocated, so that a landscape style meeting the local cultural style is created.

\section{AN INTRODUCTION TO THE TYPES OF LANDSCAPE ACCESSORIES}

Landscape accessory in the landscape design of the environmental art, because of the vegetation types and the characteristics of featured landscape, is often divided into decorative landscape and functional landscape. The role of desk and chair in people's rest, the role of ads in providing information, and the role of garden lamp in lighting are the use functions of featured landscape. However, sculpture, painting, and waterscape are the decorative functions of featured landscapes.

\section{A. Decorative Landscape Accessories}

Decorative landscape accessory is essentially playing a decorative role in the environmental art for creating a kind of space art. It plays an important role in the development of urban landscape, but only the creative collocation and combination can highlight the function of highlighting the urban green space landscapes. Thus, it looks more fashionable, concise, novel, and unconventional, and also has been widely applied to urban landscape design.

1) Featured Waterscape: As the name implies, featured waterscape is naturally around water, so the designers should implement creation and design according to the different geographical, climate, and temperature differences and also in combination with their own or users' needs. Waterscape is often divided into still waterscape and flowing waterscape. Flowing waterscape under the characteristics of water movement includes fountain waterscape, waterfall waterscape, stream waterscape, pond waterscape, etc. Still waterscape includes Kunming Lake in Beijing, West Lake in Hangzhou, and other small pools. In the current urban landscape design, featured waterscape is often a necessary place for visitors to enjoy and play; featured waterscape is designed according to the high-low terrain difference and also gives a reflection to the landscape effect in a natural form by combining the design style of the surrounding environment, and produces a finishing point effect on the urban environment art.

2) Sculpture Landscape: The development of the landscape industry has driven the widespread application to sculpture landscape. In the urban environment landscape design, sculpture landscape has become an indispensable decoration in urban areas, gardens, offices, etc. In the landscape design of the urban environmental art and especially garden design, many landscapes are designed on the basis of sculpture landscape and named mostly with the name of the designers and the sculpture stories. Sculpture landscape gives a reflection to the distinctiveness and subjectivity of landscape garden and tells the tourists many stories so that the interest of the tourists in appreciating it increases. Sculpture landscape is of great significance to improving urban culture, cultural connotation, and artistic grade, and simultaneously it can promote the rapid development of the regional economy.

3) Closed and Obstructed Landscape: There is an important landscape in the landscape design, which refers to the ornamental landscape consisting of a variety of vegetation, facilities, and en-framed sceneries. This is called as closed and obstructed landscape. It mainly includes four parts: open space, half-open space, closed space, and open space. Open space makes low shrubs and surface plants generate an open, flowing space; half-open space becomes a one-way closed space by high and low vegetation on both sides in order to highlight the direction of the landscape; closed space is limited in all directions by low shrubs on the horizontal space, for the main purpose of isolating with the surrounding environment; open space, by the utilization of lush branches and leaves, makes a top surface emerge, which is a horizontal space relative the ground.

\section{B. Functional landscapes}

1) Lighting landscape: In order to highlight the vertical feelings sourcing from the landscape, lighting elements such as ground lamp, street lamp, and spotlight are often added into lighting landscape. In the design of lighting landscape, the designers will often give full consideration to the landscape style and choose the lamps and lanterns fit the landscape. However, the practicality of c lighting landscape design should be considered when the ornamental element is taken into account, in order to ensure the quality of materials and the integrity of the landscape.

2) Displaying facilities: When enjoying and touring in a scenic spot, tourists may get lost and cannot find the direction, and then some instructive and guides are necessary. Display facilities play an instructing, publicizing, and guiding role in landscape. The creativity for the display facilities can not only make the 
information more clear, but also can play the main characteristics of beauties, so that tourists can love the urban areas unknowingly. Therefore, display facilities are the integral parts of the urban areas.

3) Rest facilities: Rest facilities installed in the landscapes can not only help alleviate the fatigue of tourists and improve the utilization rate of landscapes and the interest of tourists, but also can provide rest, entertainment venues such as pavilions, corridor, and chairs for tourists. To carry on the design of rest facilities in the landscapes, the use requirements of people should be primarily considered and also the design styles of the environment landscapes are combined, making the rest facilities complete, harmonious, and unified.

\section{CONCLUSION}

The landscape design of the environmental art is a comprehensive subject with higher technical and creative requirements. To really do a good job in the landscape accessories in landscape design, it is necessary to be based on the environmental art and get a thorough understanding of the whole urban style, so that the functional and decorative characteristics of landscape accessory design meet the needs of the urban areas and people in combination with geography, culture, humanities, folk customs, and other factors, and the rapid development of economy in China can be promoted when the urban cultural artistic style is improved.

\section{REFERENCES}

[1] Yinan CHENG. Discussion on the Ecological Design of Featured Forest Park Landscapes [D]. Chinese Academy of Forestry, 2013.

[2] Bin YU. Research on the Featured Park Landscapes based on the Regional Culture [D]. Fujian Agriculture and Forestry University, 2013.

[3] Jing Lang, Sizhuo LI. Featured Landscapes in Urban DesignDiscussion on the Role of Landscape Design [J]. Architectural Design Management, 2008, 03:38-40.

[4] Liyue WANG. Research on the Featured Landscape Design based on the Regional Culture [D]. Nanjing Forestry University, 2012.

[5] Rong MA. Research on the Aesthetic Application to Featured Landscape Design [D]. Northwest A\&F University, 2012.

[6] Jundong YE. Landscape Sculpture in Qiang Landscape Environmental Art Design [J]. Contemporary Art, 2012, 03:17-19.

[7] Yong YANG. "Symbiosis" in the Urban Featured Landscape Design [D]. Hunan Normal University, 2011. 